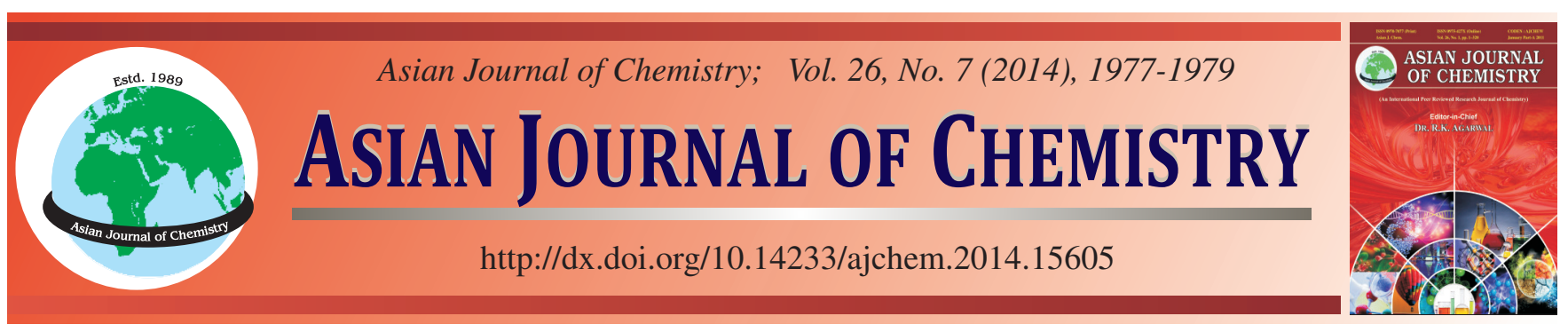

\title{
Determination of Half-life of Dissolution Process of Oxaliplatin in DMSO
}

\section{J.L. SuO ${ }^{*}$, X.H. Pu and W.W. ZHAO}

Key Laboratory For Phytochemistry of Shaanxi Province, College of Chemistry and Chemical Engineering, Baoji University of Arts and Sciences, No. 1 Hi-Tech Avenue (New Campus), Baoji 721013, Shaanxi Province, P.R. China

*Corresponding author: E-mail: baowenlihuaxue@163.com

The enthalpies of dissolution for oxaliplatin in dimethyl sulfoxide were measured using a RD496-CK2000 calve microcalorimeter at 309.65 K under atmospheric pressure. Differential enthalpies and molar enthalpies were determined for oxaliplatin in dimethyl sulfoxide, then the relationship of the heat effect of each process with the amount of the substance was setted up. On the basis of the dynamics equation, the process of dissolution is a pseudo first order reaction was indicated. Meanwhile, the half-life period $\mathrm{t}_{1 / 2}=59.32 \mathrm{~min}$, the molar enthalpy $\Delta_{\mathrm{sol}} \mathrm{H}_{\mathrm{m}}=14.996 \mathrm{~kJ} \mathrm{~mol}^{-1}$, the molar gigs free energy $\Delta_{\mathrm{sol}} \mathrm{G}_{\mathrm{m}}=97.93 \mathrm{~kJ} \mathrm{~mol}^{-1}$, the molar entropy is $\Delta_{\mathrm{sol}} \mathrm{S}_{\mathrm{m}}=-267.81 \mathrm{~J} \mathrm{~mol}^{-1} \mathrm{~K}^{-1} \mathrm{were}$ calculated. The result not only provides a simple method for the detemination of the half-life for drugs, but also offer a theoretical reference for the clinical application of oxaliplatin

Keywords: Thermodynamics, Kinetics, Dissolution heat, Half-life, Oxaliplatin.

\section{INTRODUCTION}

The systematic name of oxaliplatin is oxalato (trans-(-)1,2-cyclohexanediamine) platinum (II), for short L-OHP. It was synthesized by the Japan's Kidani in 1978 at first. Following the cisplatin and carboplatin, it was called the third generation of platinum anticancer drugs, which was developed by Swiss Debiopharm company, produced and soled by Sanofi company in France in 1996. Now it is applied by many countries including the United States ${ }^{1-6}$. Meanwhile, capecitabine platinum developed successfully by Nanjing pharmaceutical in China, which was qualified for new drug registration and quality certification. But its unique mechanism of action and high anticancer activity were focused by the international medical community on tumor. Academic researchers on drugs have obtained the half life based on the principle of pharmacokinetics using HPLC to detect the drug concentration in blood. It is an effective method, but the procedure is complicated ${ }^{7,8}$. So a simple and feasible method to carry out experiments and to draw reliable data is particularly important.

Aiming at the above problems, we have gained the halflife of the drug by calorimetry. The conclusions showed that the results obtained by the calorimetry method were tallied with what by the pharmacokinetics. It is easy to be operated. Therefore, it will have an important significance to enhance the quality of medicines by studying its thermodynamic functions and determining the kinetic parameters.

\section{EXPERIMENTAL}

Oxaliplatin (99\%, Kunming Guiyan Pharmaceutical Co., Ltd.). DMSO: analytically pure.

Equipment and conditions: The experiment was performed using a RD496-2000 Calvet Microcalorimeter (Mianyang CAEP Thermal Analysis Instrument Company, China). The microcalorimeter was calibrated by Joule effect and its sensitivity was $64.22 \pm 0.04 \mu \mathrm{V} \mathrm{mW}^{-1}$ at $309.65 \mathrm{~K}$. The enthalpy of dissolution of $\mathrm{KCl}$ (spectrum purity) in distilled water (about $20 \mathrm{mg} / 2.00 \mathrm{~g}$ ) measured at $298.15 \mathrm{~K}$ was $17.535 \mathrm{~kJ} \mathrm{~mol}^{-1}$, which was in an excellent accordance with the literature value ${ }^{9}$ $17.536 \mathrm{~kJ} \mathrm{~mol}^{-1}$, showing that the device of measuring the enthalpy used in this work was reliable.

The proper quality of oxaliplatin $(12.65 \mathrm{mg}, 13.22 \mathrm{~mL}$, $14.43 \mathrm{~mL}, 15.30 \mathrm{~mL}, 15.95 \mathrm{~mL}$ ) were dissolved in DMSO with $1.50 \mathrm{~mL}$, respectively, at $309.65 \mathrm{~K}$ under the atmospheric pressure. The enthalpy change of the process was detected by the RD496-2000 Calvet Microcalorimeter.

\section{RESULTS AND DISCUSSION}

Thermochemical behaviours of the dissolution of oxaliplatin: The certain quality of oxaliplatin was dissolved in DMSO at $309.65 \mathrm{~K}$. There are five concentration gradients to carry out in this experiment. The curve describing the entire dissolution process of oxaliplatin in DMSO is shown in Fig. 1. The dissolution is of an exothermic process. The entire process 
was repeated three times. The heat flow curves obtained under the same conditions overlap with each other, indicating that the reproducibility of the test is satisfactory.

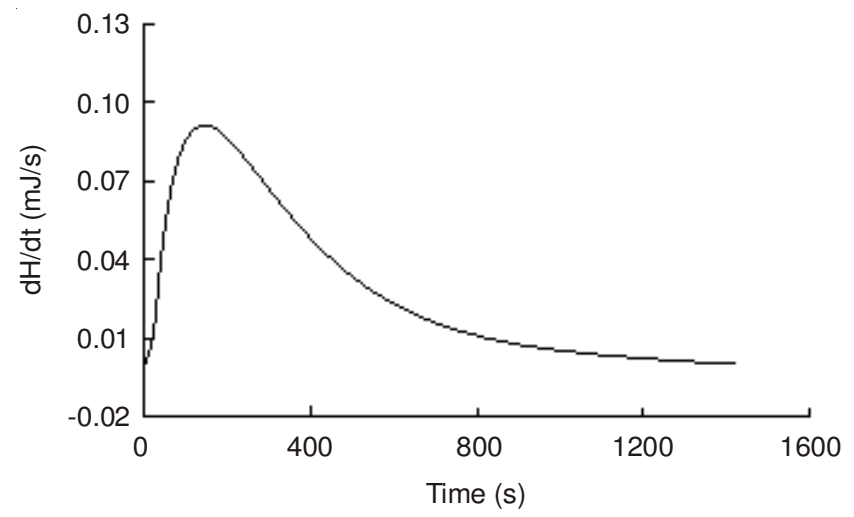

Fig. 1. Heat release rate $(\Delta \mathrm{H} / \Delta \mathrm{t})$ in the entire dissolution process of oxaliplatin in DMSO

Table- 1 shows the experimental data obtained from the typical thermogram curve of the dissolution with different volume mixture solution B in 1.5 mL DMSO.

\begin{tabular}{|c|c|c|c|}
\hline \multicolumn{4}{|c|}{$\begin{array}{c}\text { TABLE-1 } \\
\text { ENTHALPIES OF DISSOLUTION OF OXALIPLATIN IN DMSO }\end{array}$} \\
\hline $\begin{array}{l}\text { Sample mass } \\
(\mathrm{mg})\end{array}$ & $\mathrm{n} /\left(\times 10^{-3} \mathrm{~mol}\right)$ & $\mathrm{Q}(\mathrm{mJ})$ & $\Delta_{\mathrm{so}} \mathrm{H}_{\mathrm{m}}\left(\mathrm{J} \mathrm{mol}^{-1}\right)$ \\
\hline 12.65 & 0.032 & 470.87 & 14713.11 \\
\hline 13.22 & 0.033 & 495.67 & 14820.23 \\
\hline 14.43 & 0.037 & 545.91 & 14953.70 \\
\hline 15.30 & 0.039 & 591.53 & 15281.96 \\
\hline 15.95 & 0.040 & 613.96 & 15215.05 \\
\hline Average & & & 14996.81 \\
\hline
\end{tabular}

Table-1 showed the concentrations of the solution almost have little influence on the values of the molar enthalpy $\left(\Delta_{\mathrm{sol}} H_{\mathrm{m}}\right)$ at $309.65 \mathrm{~K}$. So the average value of $\Delta_{\text {sol }} H_{\mathrm{m}}$ which is $14.996 \mathrm{~kJ}$ $\mathrm{mol}^{-1}$ can represent the molar enthalpy of the infinite diluted DMSO at $309.65 \mathrm{~K}$.

The heat effect $v s$. the amount of the substance relationships of oxaliplatin in DMSO is shown in Fig. 2.

The linear equation for the DMSO is as follows:

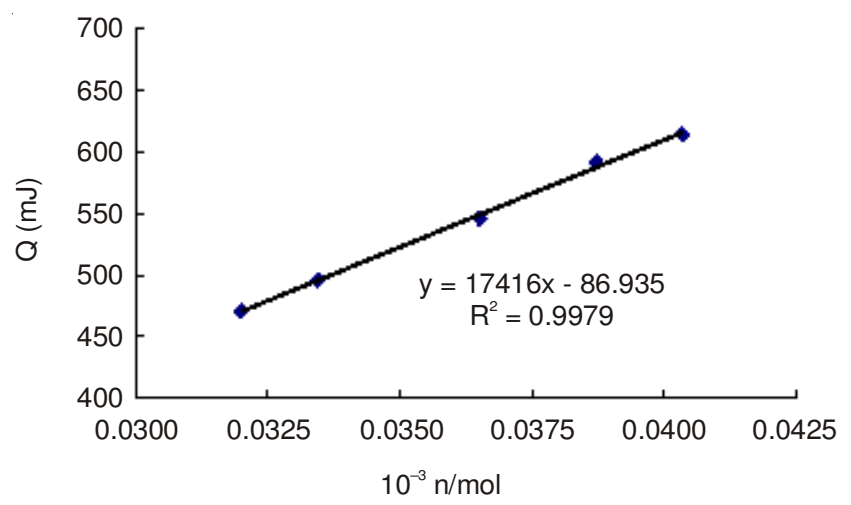

Fig. 2. Relationship between the amount of oxaliplatin (n) and the heat $\mathrm{Q}$ dissolved in DMSO

$$
\mathrm{Q}=17416000 \mathrm{n}-86.935, \mathrm{r}=0.9989
$$

where, $r$ is correlation coefficient.

The differential enthalpy $\left(\Delta_{\mathrm{dif}} H_{\mathrm{m}}\right)$ is obtained from the equation (1).

Kinetics of dissolution process of oxaliplatin in DMSO: The kinetic equation describing the dissolution of oxaliplatin in $\mathrm{DMSO}^{8}$ is eqns. 2 and 3 is chosen as the model function describing the process:

$$
\begin{aligned}
\frac{\mathrm{d} \alpha}{\mathrm{dt}} & =\mathrm{kf}(\alpha) \\
\mathrm{f}(\alpha) & =(1-\alpha)^{\mathrm{n}}
\end{aligned}
$$

Combining eqns. 2 and 3, substituting $\alpha=\frac{\mathrm{H}_{1}}{\mathrm{H}_{0}}$ into the equation and then get a logarithmic converter:

$$
\operatorname{In}\left[\frac{1}{\mathrm{H}_{0}}\left(\frac{\mathrm{dH}}{\mathrm{dt}}\right)_{\mathrm{i}}\right]=\ln \mathrm{k}+\mathrm{n} \operatorname{In}\left[1-\left(\frac{\mathrm{H}}{\mathrm{H}_{0}}\right)_{\mathrm{i}}\right] \mathrm{i}=1,2, \ldots, \mathrm{L}
$$

In these kinetic function; $\mathrm{H}$ represents the heat at time of $\mathrm{t}$; $\mathrm{H}_{0}$ is the heat of the whole process; $\mathrm{k}$ is the dissolution rate constant of oxaliplatin in DMSO; $\mathrm{n}$ is the reaction order and $\mathrm{L}$ is the counting number.

By substituting the data taken from Table-2, $(\mathrm{dH} / \mathrm{dt})_{\mathrm{i}}$, $\left(\mathrm{H} / \mathrm{H}_{\infty}\right)_{i}, \mathrm{H}_{\infty}, \mathrm{i}=1,2, \ldots, \mathrm{L}$, into the kinetic eqn. 4 , the obtained values of $\mathrm{n}$ and lnk are listed in Table-2.

\begin{tabular}{cccccc}
\multicolumn{5}{c}{ TABLE-2 } \\
& $\begin{array}{c}\text { EXPERIMENTAL DATE OF OXALIPLATIN } \\
\text { DISSOLVED IN 1.50 mL DMSO SOLUTION }\end{array}$ & \\
\hline $\mathrm{m}(\mathrm{mg})$ & $\mathrm{t}(\mathrm{s})$ & $\begin{array}{c}\mathrm{dH} / \mathrm{dt} \\
\left(\mathrm{mJ} \mathrm{s}^{-1}\right)\end{array}$ & $\mathrm{H}_{\mathrm{t}}(\mathrm{mJ})$ & $\mathrm{H}_{\mathrm{t}} / \mathrm{H}_{\mathrm{o}}$ & $\begin{array}{c}\mathrm{H}_{\infty}(\mathrm{kJ} \\
\left.\mathrm{mol}^{-1}\right)\end{array}$ \\
\hline & 0 & 0.079 & 172.2 & 0.366 & \\
& 20 & 0.075 & 196.1 & 0.416 & \\
& 40 & 0.071 & 218.8 & 0.465 & \\
& 60 & 0.067 & 240.2 & 0.510 & \\
& 80 & 0.063 & 260.4 & 0.553 & \\
& 100 & 0.059 & 279.3 & 0.593 & \\
& 120 & 0.055 & 297.0 & 0.631 & \\
& 140 & 0.051 & 313.4 & 0.666 & \\
& 160 & 0.047 & 328.6 & 0.698 & \\
& 180 & 0.044 & 342.7 & 0.728 & \\
\hline
\end{tabular}

Note: The data of Oxaliplatin $(13.22 \mathrm{mg}, 14.43 \mathrm{mg}, 15.30 \mathrm{mg}, 15.95$ $\mathrm{mg}$ ) dissolved in DMSO with $1.50 \mathrm{~mL}$ were omitted for verbosity.

Substituting the values of $\mathrm{n}$ and $\mathrm{k}$ in Table- 3 into eqns. 2 and 3 and then uniting them, the kinetic equation of the dissolution process can be deduced to be

$$
\frac{\mathrm{d} \alpha}{\mathrm{dt}}=10^{-3.71}(1-\alpha)^{0.93}
$$

TABLE-3

AT 309.65 K THE REACTION SERIES n AND $\ln \mathrm{k}$ OF OXALIPLATIN DISSOLVED IN $1.50 \mathrm{~mL}$ DMSO SOLUTION

\begin{tabular}{cccc}
\hline Sample mass $(\mathrm{mg})$ & $\mathrm{n}$ & $\ln \mathrm{k}$ & $\mathrm{r}$ \\
\hline 12.65 & 0.72 & -8.36 & 0.9996 \\
13.22 & 1.12 & -8.85 & 0.9996 \\
14.43 & 1.02 & -8.56 & 0.9996 \\
15.30 & 0.91 & -8.48 & 0.9995 \\
15.95 & 0.89 & -8.46 & 0.9995 \\
Average & 0.93 & -8.54 & 0.9996 \\
\hline
\end{tabular}


The kinetic equation is similar to quasi-first order reaction of the dissolution process. So the half-life period can be calculated with eqn. 5 and its value is $59.32 \mathrm{~min}$.

$$
\mathrm{t}_{1 / 2}=\frac{\ln 2}{\mathrm{k}}
$$

Thermodynamics of oxaliplatin in DMSO: On the basis of these experimental data and calculated results, the kinetic parameters of the dissolution process were inferred through eqn. 7.

$$
\text { In } \frac{\mathrm{k} \cdot \mathrm{h}}{\mathrm{k}_{\mathrm{B}} \cdot \mathrm{T}}=\frac{\Delta_{\mathrm{sol}} \mathrm{S}_{\mathrm{m}}}{\mathrm{R}}-\frac{\Delta_{\mathrm{sol}} \mathrm{H}_{\mathrm{m}}}{\mathrm{RT}}
$$

Substituting $\mathrm{k}_{\mathrm{B}}=1.380 \times 10^{-23} \mathrm{~J} \mathrm{~K}^{-1}, \mathrm{~h}=6.626 \times 10^{-34} \mathrm{~J} \mathrm{~s}$ $\mathrm{R}=8.314 \mathrm{~J} \mathrm{~mol} \mathrm{k}^{-1}, \Delta_{\mathrm{so}} \mathrm{H}_{\mathrm{m}}=14.996 \mathrm{~kJ} \mathrm{~mol}^{-1}, \mathrm{~T}=309.65 \mathrm{~K}$, so $\Delta_{\text {sol }} S_{\mathrm{m}}=-267.81 \mathrm{~J}$.

And then putting $\Delta_{\text {sol }} H_{m}$ and $\Delta_{\text {sol }} S_{\mathrm{m}}$ into the following formula

$$
\Delta_{\text {sol }} \mathrm{G}_{\mathrm{m}}=\Delta_{\mathrm{sol}} \mathrm{H}_{\mathrm{m}}-\mathrm{T} \Delta_{\mathrm{sol}} \mathrm{S}_{\mathrm{m}}
$$

We can ascertain $\Delta_{\mathrm{sol}} \mathrm{G}_{\mathrm{m}}=97.93 \mathrm{~kJ} \mathrm{~mol}^{-1}$.

\section{Conclusions}

- The experiment results show that microcalorimeter method can obtain the half-life of drug easily.

- The kinetic equation of the dissolution process of oxaliplatin in DMSO at $309.65 \mathrm{~K}$ is $\frac{\mathrm{d} \alpha}{\mathrm{dt}}=10^{-371}(1-\alpha)^{0.93}$. It is a quasi-first order reaction and its half-life is $t_{1 / 2}=59.32$ $\min$, the rate constant $\mathrm{k}=1.96 \times 10^{-4} \mathrm{~s}^{-1}$.
- The dissolution of oxaliplatin in normal saline is an exothermic process. The molar enthalpy $\left(\Delta_{\text {sol }} \mathrm{H}_{\mathrm{m}}\right)$ is $14.996 \mathrm{~kJ}$ $\mathrm{mol}^{-1}$ and $\Delta_{\text {sol }} \mathrm{S}_{\mathrm{m}}$ is $-267.81 \mathrm{~J} \mathrm{~mol}^{-1} \mathrm{~K}^{-1}$. The negative value of entropy of activation indicates that the dissolution of oxaliplatin in DMSO get a more ordered system.

\section{ACKNOWLEDGEMENTS}

The authors are grateful to the support of the Phytochemistry Key Laboratory of Shaanxi Province for the research grant (No. 12JS006), the Project of Development Programs in Science and Technology of Shaanxi Province (No. 2012JM2019) and the School-Level Key Scientific Research Projects of Baoji University of Arts and Sciences (No. ZK11046) of China.

\section{REFERENCES}

1. Y. Kidani and K. Inagaki, cis-Platinum(II) complex of trans-1-1,2diaminocyclohexane, US Patent 4169846 (1979).

2. J. Capdevila, E. Elez, S. Peralta, T. Macarulla, F.J. Ramos and J. Tabernero, Expert Rev. Anticancer Ther., 8, 1223 (2008).

3. N. Sawabu, Nippon Shokakibyo Gakkai Zasshi, 100, 645 (2003).

4. J. Trédaniel, C. Becht, M. Bekradda, H. De Cremoux, J. Alexandre, F. Chomy, S. Szyldergemajn, Y. Yataghene and S. Culine, Lung Cancer, 63, 259 (2009).

5. A. Gunnlaugsson, H. Anderson, E. Fernebro, E. Kjellén, P. Byström, Å. Berglund, M. Ekelund, L. Påhlman, T. Holm, B. Glimelius and A. Johnsson, Eur. J. Cancer, 45, 807 (2009).

6. Z. Wang, J. Zhou, J. Fan, S.-J. Qiu, Y. Yu, X.-W. Huang, J. Sun, C.-J. Tan and Z. Dai, Expert Opin. Investig. Drugs, 18, 1595 (2009).

7. W.L. Lin, D.G. Li, Q. Chen, H.M. Lu, X.M. Ma and P.L. Sun, World Chin. J. Digestol., 11, 1535 (2003).

8. M. Galanski, A. Yasemi, M.A. Jakupec, N. Grafv. Keyserlingk and B.K. Keppler, Monatsh. Chem., 136, 693 (2005).

9. R.L. Montgomery, R.A. Melaugh, C.-C. Lau, G.H. Meier, H.H. Chan and F.D. Rossini, J. Chem. Thermodynamics, 9, 915 (1977). 